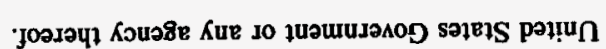

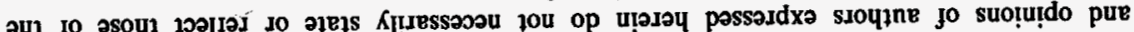
әप J (1)

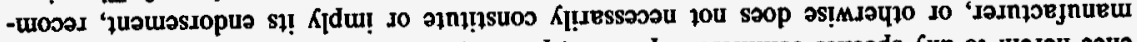

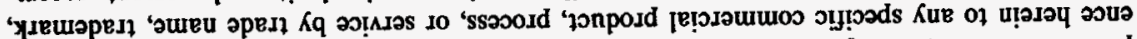

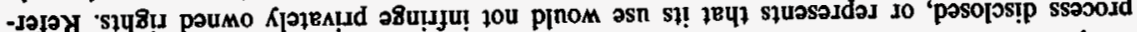
10 '

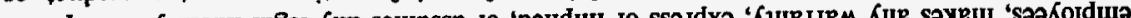

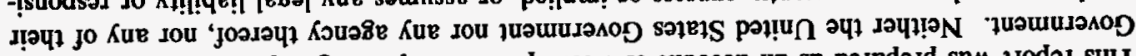
səje1S peł!u

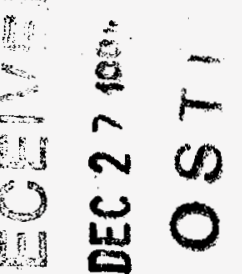

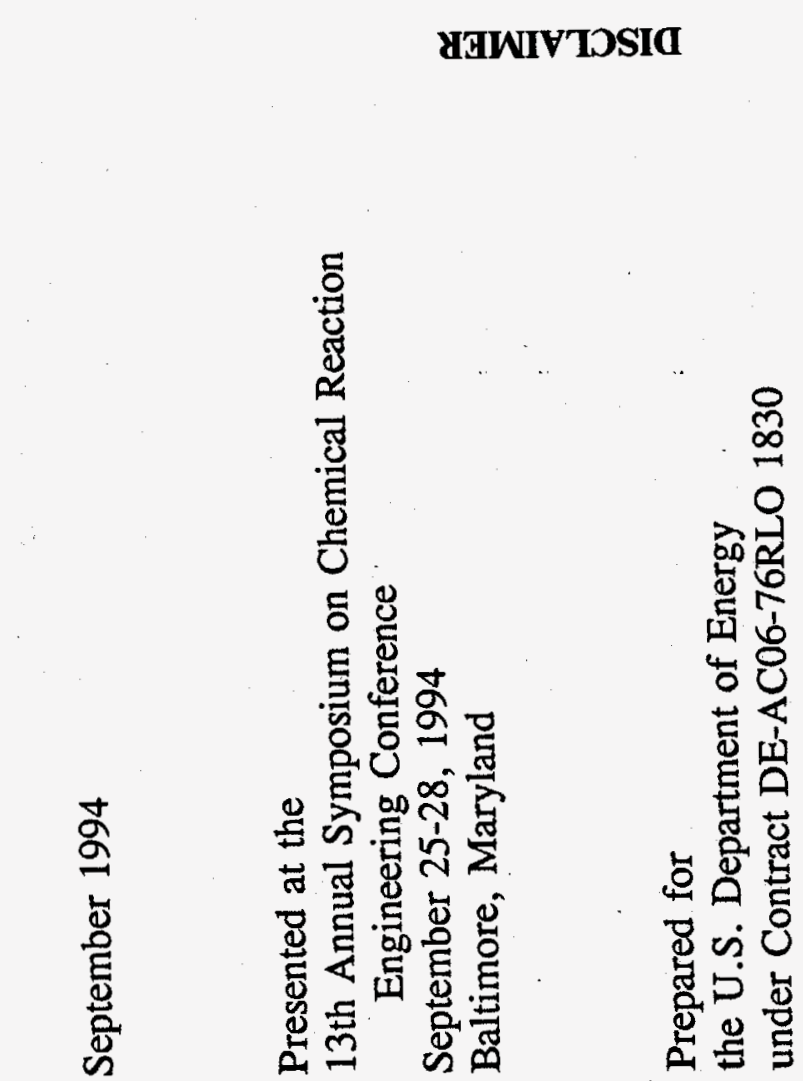




\section{DISCLAIMER}

Portions of this document may be illegible in electronic image products. Images are produced from the best available original document. 


\title{
A Simulated Countercurrent Moving-Bed Chromatographic Reactor for the Oxidative Coupling of Methane: Experimental Results
}

\author{
Anna Lee Y. Tonkovich \\ Pacific Northwest Laboratory, Richland, WA 99352 \\ Robert W. Carr \\ Department of Chemical Engineering and Materials Sciences \\ University of Minnesota, Minneapolis MN 55455
}

\begin{abstract}
:
The oxidative coupling reaction of methane (OCM) represents a potential commercial ethylene production route. Natural gas is primarily methane and in worldwide abundance; therefore, the conversion of natural gas to ethylene has implications for reducing energy use, pollution, and dependence on foreign oil reserves. However, OCM production routes are not yet economically viable given the low product yields per pass. The highest reported yields do not exceed $20 \%$.

The methane coupling reaction is accompanied by the undesired conversion of methane to carbon oxides. The relative amount of oxygen and methane along with other parameters, including temperature, determine the favored reaction pathway. High hydrocarbon to oxygen feed ratios give high ethane/ethylene selectivities but at the expense of the hydrocarbon conversion. When the methane to oxygen feed ratio is low, combustion is favored.

The simulated countercurrent moving-bed chromatographic reactor (SCMCR) is applied to the OCM. A modified experimental configuration is designed and evaluated. A four-section apparatus, each containing a reaction and two separation columns, is used to quickly separate the reactants and products using the principles of simulated countercurrent flow. Simultaneous reaction and separation of the reactive products column is desired, but unattainable because of an incompatibility between $O C M$ reaction and separation temperatures.

Microreactor yields with a samarium oxide catalyst gives yields between $2 \%$ and $10 \%$. Yields as high as 50\% are observed with the same catalyst and run conditions in the SCMCR. These yields are significantly higher than previously reported values. The effects of temperature, feed switching time, and methane to oxygen feed ratio have been investigated. The reactor, while not fully optimized, does give promise as an alternative production method for ethylene.
\end{abstract}




\section{Introduction:}

The simulated countercurrent moving-bed chromatographic reactor (SCMCR) is a novel separative-reactor. Countercurrent flow is simulated to approximate in situ product and reactant separation. This reactor increases the conversion for equilibrium-limited and partial oxidation reactions that are inhibited by the co-presence of reactants and products. The SCMCR either prevents local reactant-product equilibrium or inhibits overoxidation in partial oxidation reactions by separation of the more reactive intermediate product.

This paper describes experimental results using a modified version of the SCMCR to enhance the yields of the oxidative coupling reaction of methane (OCM). This reaction is of particular importance because ethylene is a precursor for many other reactions. Methane is the primary constituent in natural gas and is in abundance worldwide (Bhasin 1988). High economic transport costs of gaseous substances, or of liquefied natural gas, limit the full range of applications for methane. Reacting methane to a useful liquid-fuel precursor will place an increased demand on the methane supply, while also decreasing the demand for other fossil fuels (Keller and Bhasin 1982; Scurrell 1987; Edwards and Tyler 1988; Hutchings and Joyner 1991; Sofranko et al. 1987).

The oxidative coupling reaction is crucial to the eventual transformation of methane into a useful precursor, but this reaction is not currently feasible on a large production scale because of adverse economic constraints. The conversion of methane per pass in a single fixed-bed tubular reactor is extremely low, which increases the cost of a large-scale operation. If a high selectivity to ethane and ethylene is to be achieved, the methane to oxygen ratio must be kept very high (greater than 20:1). However, by keeping this ratio high, the conversion of methane decreases significantly. Stoichiometrically, 4 moles of methane react with 1 mole of oxygen to form 2 moles of ethane, thus ratios above 4:1 result in much lower methane conversions. As the conversion decreases, increased capital and operating expenses are incurred because of the necessity of separating the small product fraction and recycling the remaining reactants.

The SCMCR addresses the problem of maintaining a high ratio for selectivity constraints while also feeding enough oxygen to obtain reasonable methane conversions. This reactor builds upon 
the principles of simulated countercurrent flow, as well, to discretely approximate simultaneous reaction and separation.

\section{Background:}

The original concept of the SCMCR is similar to the simulated countercurrent separator (SCCS) (Fish et al. 1988, 1993; Ray et al. 1990, 1994; Tonkovich et al. 1994). Countercurrent flow is simulated by moving the feed port past fixed adsorbent beds at a rate between the breakthrough times of a binary mixture. The weakly adsorbed component elutes from the feed column first. Prior to breakthrough of the strongly adsorbed component, the feed is switched one column to the left. The strongly adsorbed component remains behind the moving-feed port, and is desorbed with a separate carrier stream several switches later. Countercurrent flow is simulated because the weakly adsorbed component is moving faster than the feed port, while the strongly adsorbed component is moving more slowly.

The inclusion of a reaction in this system is aided by the mixing of an adsorbent with a catalyst to facilitate simultaneous reaction and separation. The products are weakly adsorbed and move quickly out of the system. The continuous reactant feed stream is switched from column to column before the reactant elutes. The optimal number of columns in this design is unclear for the reactor/șeparator but will likely be analogous to that for the SCCS and equal to three or four columns depending upon the need for a purge stream (Tonkovich et al. 1994).

The original SCMCR design is applicable for some reactions. This reactor has been investigated for the mesitylene dehydrogenation reaction (Ray et al. 1994). This reaction is strongly equilibrium-limited, which does not allow complete conversion per pass. The reaction products are weakly adsorbed relative to the mesitylene reactant. Operating with a five-column SCMCR design improves the reactant conversion from $62 \%$ to over $85 \%$, and gives product purities near $95 \%$.

The original SCMCR design is not applicable for all reactions. If reaction temperatures exceed the range of usable adsorbent operating temperatures, this design cannot be applied. In addition, if 
the products are strongly adsorbed relative to the reactants, i.e., the elution order is reversed, then design modifications may be necessary. The design described in this paper addresses these issues for the OCM.

\section{Reaction network:}

Methane couples in the presence of oxygen to form ethane and water. Ethane further reacts with oxygen to form ethylene and water. The primary side reaction is the complete oxidation of methane to form carbon dioxide. The primary reactions are presented in Equations (1-3).

$$
\begin{aligned}
& 2 \mathrm{CH}_{4}+\frac{1}{2} \mathrm{O}_{2} \rightarrow \mathrm{C}_{2} \mathrm{H}_{6}+\mathrm{H}_{2} \mathrm{O} \\
& \mathrm{C}_{2} \mathrm{H}_{6}+\frac{1}{2} \mathrm{O}_{2} \rightarrow \mathrm{C}_{2} \mathrm{H}_{4}+\mathrm{H}_{2} \mathrm{O} \\
& \mathrm{CH}_{4}+2 \mathrm{O}_{2} \rightarrow \mathrm{CO}_{2}+2 \mathrm{H}_{2} \mathrm{O}
\end{aligned}
$$

The oxidative coupling reaction occurs catalytically and at elevated temperatures. Methane forms methyl radicals on the catalyst surface, desorbs, and couples homogeneously in the gas phase to form ethane and ethylene (Anderson 1989; Campbell et. al. 1987; Campbell and Lunsford 1988a; Driscoll and Lunsford 1985; Hutchings et al. 1988; Ito et al. 1985; Iwamatsu et al. 1988; Lunsford 1990; Sofranko et al. 1987; Tong et a. 1989). There is a trade-off between high selectivity and activity. Catalysts that give a high conversion of methane do not always exhibit high selectivity to ethane and ethylene, and those that give a high selectivity are not extremely active.

Samarium oxide was selected as the catalyst for the modified SCMCR in consideration of this trade-off. In particular, it exhibits high selectivity to ethane and ethylene (Deboy and Hicks 1988; Otsuka et al. 1985, 1986a-d; Otsuka and Jinno 1986; Otsuka and Komatsu 1987; Otsuka 1990; Campbell et al. 1988b; Ekstrom and Lapszewicz 1988a-b). Although the activity of this oxide catalyst is low, it makes a good choice for use in the SCMCR. Since the reactor is designed to 
enhance the overall methane conversion, a catalyst showing high selectivity to the desired products (ethane and ethylene) is preferred.

\section{Experimental:}

The experimental apparatus was constructed to facilitate the oxidative coupling reaction of methane to ethane and ethylene (Tonkovich et al. 1993). The original SCMCR design contains a series of columns co-packed with an adsorbent and catalyst to facilitate continuous product separation, and is configured analogously to the SCCS optimal design. Although this design works well for some reactions, it is not applicable for the OCM because most adsorbents will not maintain structural integrity, or will not exhibit enought adsorption selectivity at the high temperatures required for reaction. The original and modified configurations of the SCMCR are shown in Figure 1.

The first modification reconciles the high reaction temperatures and the lower operating temperatures of the adsorbent by placing catalyst and adsorbent in series, so the temperatures can be separately controlled. The modified SCMCR is analogous to the SCCS, where four sections remain within the reactor. Each section contains a high-temperature reaction column followed by a low-temperature separation column to quickly separate the products and prevent overoxidation.

The second SCMCR modification addresses the reversed reactant and product elution order. The products (ethane and ethylene) are more strongly adsorbed than methane on most adsorbents. During the operation of the SCMCR, the unconverted reactants (methane and oxygen) are stored in the current feed section separation column. Prior to methane breakthrough (and material loss), the feed is switched to the next section. The carrier gas enters the section behind the feed, desorbs stored reactants, and adds them to the feed entering the new reaction column. The products are rapidly removed from the reaction conditions in the low-temperature separation column, which prevents further decomposition. A pure product stream is removed two sections behind the feed section with the aid of a separate carrier gas. 
The final SCMCR modification is the use of a make-up feed for all cycles after the first column switching. Excess methane is charged to the system during the first cycle, and is retained during all subsequent switches. This initial methane charge ensures that the in situ methane to oxygen ratio is always high (greater than 50:1) to obtain high ethane/ethylene selectivities. A make-up feed is added during all cycles after the first to augment the small fraction of reactants that are lost during the previous cycle. This allows feed ratios near stoichiometric proportions to be added to the system at steady state (on the order of $2: 1$ to $4: 1$ ), thus enabling high methane conversions. Make-up feed rates of methane may have to be slightly greater than the amount reacted per pass to compensate for other methane losses from tailing and the like. Ideal concentration profiles for this reactor are presented in Figure 2.

\section{Reaction columns:}

Quartz reaction columns are used to withstand the elevated temperatures and to provide an inert surface. Stainless steel columns coke under reaction conditions and promote combustion. The columns have a 1/4-in. outside diameter and are $20 \mathrm{in}$. long. The ends of each column are fitted with teflon ferrules to connect to 1/8-inch stainless steel tubing. All reaction columns are housed within a Thermolyne 21100 tube furnace.

The catalyst, a pure samarium oxide powder from Aldrich Chemicals, Inc., is packed in the center of the quartz tube. A small plug of catalyst (70 $\mathrm{mg}$ and approximately $3 \mathrm{~mm}$ in length) is packed in between larger plugs of quartz wool.

\section{Separation columns:}

Activated charcoal from Alltech, Inc., is used to separate methane from the reaction products (ethane and ethylene). Ethane and ethylene are more strongly adsorbed than methane and have a breakthrough time difference of approximately $8: 1$ and $6.5: 1$ with methane.

The adsorbent is packed into 1/4-in. outside diameter stainless steel tubes and maintained at $100^{\circ} \mathrm{C}$. Swagelock fittings and 1/8-in. stainless steel tubing are used to maintain all connections. 
Two separation columns, 3 in. and 4.5 in., are used. The separation column is divided to allow for efficient product removal. An additional carrier gas is used to desorb the products after the first separation column (3-in. column).

\section{Reactor performance measurement:}

Methane concentrations are measured using a 6-ft Porapak QS analytical column in a FID GC. Samples are automatically pulled every $60 \mathrm{sec}$ for analysis. The sampling time and the column switching time are offset to permit effective effluent concentration measurements at 3-sec intervals within the switching cycle. Many cycles are required to obtain the intracycle profiles for methane losses from the feed section, and for material removed from the product removal section. A steady-state mass balance is applied on the system to calculate the methane conversion and the ethane/ethylene selectivity. A known amount of methane is fed during each cycle and the conversion is taken as one minus the moles of unreacted methane removed during a switching cycle divided by the moles of methane fed during the same cycle. The selectivity is calculated as the ratio of two times the moles of ethane and ethylene formed to the total moles of methane consumed.

Quantitative analysis is done by FID GC. Height signals are calibrated as a function of mole fraction. A nitrogen carrier in the analytical GC of approximately $50 \mathrm{ml} / \mathrm{min}$ gives breakthrough times of 25,45 , and $50 \mathrm{sec}$ for methane, ethylene, and ethane, respectively.

\section{Results and Discussion:}

The samarium oxide catalyst is first evaluated in a microreactor and then tested in the modified SCMCR design. The important operating parameters of temperature, switching time, and feed ratio are investigated.

\section{Microreactor catalyst evaluation:}


A microreactor is made with a single reaction column packed with $70 \mathrm{mg}$ of the samarium oxide catalyst. The conversion and the selectivity to the desired products (ethane and ethylene) are measured for the samarium oxide catalyst. The temperature effect and the methane to oxygen ratio are determined. Ultrahigh purity (>99.9\%) methane from Air Products, Inc., and ultrahigh carrier grade air, also from Air Products, are used. The feeds are metered using low flowrate rotameters from Cole-Parmer. A nitrogen carrier gas is used and measured at the reactor exit using a bubble flowmeter.

Reactant conversions and product selectivities are calculated using the measured mole fractions in Equations (4-6).

$$
\begin{aligned}
& \text { Conv }_{\text {methane }}=\frac{\left[\mathrm{CO}_{2}\right]+2\left(\left[\mathrm{C}_{2} \mathrm{H}_{6}\right]+\left[\mathrm{C}_{2} \mathrm{H}_{4}\right]\right)}{\left[\mathrm{CO}_{2}\right]+2\left(\left[\mathrm{C}_{2} \mathrm{H}_{6}\right]+\left[\mathrm{C}_{2} \mathrm{H}_{4}\right]\right)+\left[\mathrm{CH}_{4}\right]} \times 100 \\
& \operatorname{Sel}_{\mathrm{c} 2} \mathrm{~s}=\quad \frac{2\left(\left[\mathrm{C}_{2} \mathrm{H}_{6}\right]+\left[\mathrm{C}_{2} \mathrm{H}_{4}\right]\right)}{\left[\mathrm{CO}_{2}\right]+2\left(\left[\mathrm{C}_{2} \mathrm{H}_{6}\right]+\left[\mathrm{C}_{2} \mathrm{H}_{4}\right]\right)} \times 100 \\
& \text { Convo2 }=\quad \frac{1 / 2\left[\mathrm{C}_{2} \mathrm{H}_{6}\right]+\left[\mathrm{C}_{2} \mathrm{H}_{4}\right]+2\left[\mathrm{CO}_{2}\right]}{\left[\mathrm{CH}_{4}\right]_{0} / \text { Ratio }} \times 100 .
\end{aligned}
$$

Microreactor evaluation of the catalyst shows the conversion and selectivity trade-off. Figure 3 presents the rnethane conversion and the ethane/ethylene selectivity as a function of feed ratio at $600^{\circ} \mathrm{C}, 650^{\circ} \mathrm{C}, 700^{\circ} \mathrm{C}$ and $725^{\circ} \mathrm{C}$. A nitrogen carrier gas flowrate of $100 \mathrm{~mL} / \mathrm{min}$ is used for all trials. A methane flowrate of $14 \mathrm{ml} / \mathrm{min}$ is used, and the air flowrates are adjusted to obtain the correct feed ratios.

The reactant conversions and product selectivity increases with temperature; a significant improvement in performance is observed between $650^{\circ} \mathrm{C}$ and $700^{\circ} \mathrm{C}$. The methane to oxygen ratio also plays an important role. The methane conversion decreases as the feed ratio increases, while the selectivity increases with the methane to oxygen feed ratio. This agrees with reported trends where excess oxygen improves the methane conversion but at the expense of the ethane/ethylene selectivity. 


\section{Catalyst deactivation:}

The catalyst deactivates over several months. Microreactor results show a decrease in catalytic activity and a decrease in selectivity to ethane and ethylene as the catalyst ages. Little change is observed in the first month, while a 10\% to $20 \%$ loss in activity and specificity are observed after the second month of average use.

\section{Breakthrough data :}

The nitrogen carrier gas flowrate used in all SCMCR trials is $100 \mathrm{ml} / \mathrm{min}$. At this flowrate, the breakthrough curves through one section (reaction column and two separation columns) are measured for the reactants and the products. The breakthrough time for methane is $34 \mathrm{sec}$. The breakthrough time for ethane and ethylene from both separation columns connected in series is $265 \mathrm{sec}$ and $225 \mathrm{sec}$, respectively. During the operation of the SCMCR, however, the products are withdrawn after the first separation column.

\section{Effect of switching time:}

The feed switching time is an important parameter for the operation of the SCMCR. The maximum switching time is the breakthrough time of the methane reactant. At a nitrogen carrier flowrate of $100 \mathrm{ml} / \mathrm{min}$, the breakthrough time for the methane through the reaction column and both separation columns is $34 \mathrm{sec}$. The switching times evaluated range between 20 and $33 \mathrm{sec}$. The original methane feed flowrate is $18 \mathrm{ml} / \mathrm{min}$, and an initial methane to oxygen feed ratio of approximately 50:1 is used. In subsequent switches, the methane make-up feed flowrate is dropped to 1.4 to $5.1 \mathrm{ml} / \mathrm{min}$, and the make-up feed ratio of methane to oxygen is kept between $2: 1$. and $3: 1$.

Figures 4 and 5 show the effect of switching time on the methane conversion, the product selectivity, and the yield at $700^{\circ} \mathrm{C}$ and $725^{\circ} \mathrm{C}$. At each of these temperatures, the methane conversion in a single reactor column varies and is a function of the methane to oxygen ratio. At the original feed ratio, which theoretically remains constant throughout the reactor, the methane 
conversion is between $2 \%$ and $3 \%$. Significant increases in conversion over the microreactor is observed in the SCMCR; the highest conversions produced in this reactor are $45 \%$ and $65 \%$ for $700^{\circ} \mathrm{C}$ and $725^{\circ} \mathrm{C}$, respectively.

The make-up feed rate is set at $10 \%$ to $15 \%$ of the original feed rate; this compensates for the methane losses per pass. A lower feed make-up rate should have been added, but the limitations of the experimental apparatus do not permit it.

The effect of switching time is quite pronounced. Both conversion and selectivity are a strong function of switching time. There exists an optimal switching time that maximizes conversion. At switching times either very near or far from the breakthrough time, the conversion drops. When the switching time is much less than the methane breakthrough time, the methane adsorbed during the last seconds of the previous cycle does not have enough time to desorb during the next cycle. This material will be lost in the purge stream.

As the switching time nears the breakthrough time, the conversion also drops. Since more material is added in the make-up feed than reacts away, the methane concentrates in the feed section. As the material concentrates, it no longer behaves ideally, and the convective velocity of the material increases as a function of concentration. Some methane will elute from the feed section in less than $34 \mathrm{sec}$.

The conversion is a decreasing function at both ends of the switching time spectrum because of the competing methane loss sources; therefore, a maximum must and does exist at moderate switching times. This optimal switching time is rather broad for the experimental trials, and ranges between switching times set at $70 \%$ to $90 \%$ of the original breakthrough time.

If smaller make-up feed rates could be used in the SCMCR, they might affect the range of optimal switching times. For ideal isotherms and a perfect make-up feed rate, the optimal switching time should approach the breakthrough time of the original feed rate.

The effect of switching time on selectivity is less obvious. As the switching time nears the reactant breakthrough time, the selectivity to the desired products (ethane and ethylene) decreases. The selectivity drops to $40 \%$ to $60 \%$ at switching times near the original breakthrough time, while 
rising to over $90 \%$ for switching times less than the breakthrough time. Far from the breakthrough time, larger methane losses are observed, as are unreacted oxygen losses. This additional loss will increase the in situ reactant ratio during the next cycle, and thus result in higher selectivities. Near the breakthrough time, more unreacted methane and oxygen remains within the system. This added oxygen will cycle through subsequent cycles, thus lowering reactant ratios and the product selectivity.

Effect of femperature:

libe ace othen

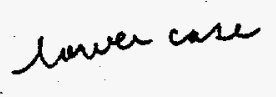

The effect of temperature on the reactor performance is also investigated. The microreactor experiments show a pronounced effect on both the reactant conversion and the product selectivity with temperature. As the temperature drops in the microreactor, the methane conversion, the oxygen conversion, and the selectivity to ethane and ethylene decrease. Identical feed rates are used in these trials. The conversion and selectivity decrease with decreasing temperature in the modified SCMCR, and are presented in Figure 6. The overall conversion decreases but not as dramatically as selectivity.

From the microreactor experiments there is a strong correlation between the reaction temperature and both the oxygen and the methane conversion. As the temperature decreases, the oxygen conversion also decreases. If less oxygen converts per pass, it will cycle through the reactor. This increase in the oxygen concentration impacts the actual in situ methane to oxygen feed ratio. As this ratio decreases, the selectivity to ethane and ethylene also decreases.

\section{Effect of methane to oxygen ratio:}

The effect of the feed ratio on the reactor performance is also investigated. The temperature and switching time are held constant as the methane to oxygen feed ratio is varied. Over a range of temperatures from $650^{\circ} \mathrm{C}$ to $775^{\circ} \mathrm{C}$ and feed ratios varying from 1.8 to 2.8 , the effect on conversion is unclear. Figure 7 shows increasing conversion and selectivity functions at $775^{\circ} \mathrm{C}$. At other temperatures, no clear trend with conversion is observed, but selectivity is always seen to 
be an increasing function with feed ratio. This is predicted from the microreactor results, which show similar behavior. However, significant differences in the feed ratios are not evaluated, and thus experimental errors may cloud the observable trends. Experimental errors are computed from the reactor performance data and reveal that the true feed ratios may be off as much as $10 \%$ to $20 \%$.

\section{Conclusions:}

The SCMCR is a novel reactor that improves otherwise low reactant conversions. The original design of the SCMCR is modified to facilitate the oxidative coupling reaction scheme. These modifications include the use of separate reaction and separation columns rather than co-packing a catalyst and adsorbent in a single column. Make-up feed flows are also a significant modification to the original SCMCR design.

The modified SCMCR experiments show improvements in reactant conversions. The selectivity is also kept high under some reaction conditions. Several parameters have a key impact on the reactor performance, including the feed switching rate, the reactor temperature, and the methane to oxygen make-up feed ratio.

Improvements in low conversion reactions, from several percent to over $60 \%$, are obtained in the modified SCMCR, while the selectivity to ethane and ethylene is kept in excess of $80 \%$ at these high conversions. In other trials, the selectivity is kept well above $90 \%$ and overall yield in some trials exceeds $50 \%$. This is a dramatic improvement from other reported tubular reactor studies, where yields do not exceed $20 \%$. Although enhanced yields are possible in this reactor, additional optimization is required.

\section{Acknowledgments:}

This work was supported by the Division of Chemical Sciences, Office of Basic Energy Sciences, U.S. Department of Energy, under contract DE-AC02-76-ER02945. 
The Pacific Northwest Laboratory is operated by Battelle Memorial Institute for the U.S.

Department of Energy under contract DE-ACo6-76RLO 1830.

\section{References:}

Bhasin, M., 1988, Feasibility of ethylene synthesis via oxidative coupling of methane, Methane conversion, Elsevier Science Publishers, Amsterdam, 343.

cap

Campbell, K., Morales, E., and Lunsford, J., 1987, Gas-phase coupling of methyl radicals during the catalytic partial oxidation of methane, J. Am. Chem. Soc., 109, 7900.

Campbell, K., and Lunsford, J., 1988, Contribution of gas-phase radical coupling in the catalytic oxidation of methane, J. Phys. Chem., 92, 5792.

Campbell, K., Zhang, H., and Lunsford, J., 1988, Methane activation by the lanthanide oxides, $J$. Phys. Chem., 92, 750.

Deboy, J., and Hicks, R., 1988, Oxidative coupling of methane over alkaline earth promoted $\mathrm{La}_{2} \mathrm{O}_{3}, J$. Chem. Soc., Chem. Commun., 982.

Driscoll, D., and Lunsford, J., 1985, Gas-phase radical formation during the reactions of methane, ethane, ethylene, and propylene over selected oxide catalysts, J. Phys. Chem., 89 , 4415.

Edwards, J., and Tyler, R., 1988, The production of liquid fuels via the catalytic coupling of methane, Methane Conversion, Elsevier Science Publishers, Amsterdam, 395.

Ekstrom, A., and Lapszewicz, J., 1988a, Methane adsorption on a working samarium oxide catalyst and its role in hydrocarbon formation during high temperature partial oxidation, $J$. Chem. Soc., Chem. Commun., 797-799.

Ekstrom, A., and Lapszewicz, J., 1988b, The role of oxygen in the partial oxidation of methane over a samarium oxide catalyst", J. Am. Chem. Soc., 110, 5226.

Fish, B., Carr, R., and Aris, R., 1988, Computer-aided experimentation in countercurrent reaction chromatography and simulated countercurrent chromatography, Chem. Eng. Sci., 43, 1867.

Fish, B., and Carr. R., and Aris, R., 1993, Design and performance of a sumulated countercurrent moving-bed separator, AlChe J., 39(11), 1783.

Hutchings, G., Scurrell, M., and Woodhouse, J., 1988, The role of gas phase reaction in the selective oxidation of methane, J. Chem. Soc., Chem. Commun., 253.

- Hutchings, G., and Joyner, R., 1991, Prospects for the partial oxidation of natural gas, Chem. \& Ind., 575.

Ito, T., Wang, J., Lin, C., and Lunsford, J., 1985, Oxidative dimerization of methane over a lithium-promoted magnesium oxide catalyst, J. Am. Chem. Soc., 107, 5062.

Iwamatsu, E., Moriyama, T., Takasaki, N., and Aika, K., 1988, Oxidative coupling of methane over promoted magnesium oxide catalysts; relation between activity and specific surface area, Methane Conversion, Elsevier Science Publishers, Amsterdam, 373. 
Keller, G., and Bhasin, M., 1982, Synthesis of ethylene via oxidative coupling of methane, $J$. Cat., 73, 9.

Lunsford, J., 1990, The catalytic conversion of methane to higher hydrocarbons, Cat. Today, 6(3), 235.

Otsuka, K., Jinno, K., and Morikawa, A., 1985, The catalysts active and selective in oxidative coupling of methane, Chem. Lett., 499.

Otsuka, K., Jinno, K., and Morikawa, A., 1986a, Active and selective catalysts for the synthesis of $\mathrm{C}_{2} \mathrm{H}_{4}$ and $\mathrm{C}_{2} \mathrm{H}_{6}$ via oxidative coupling of methane, J. Cat., 100, 353.

Otsuka, K., Liu, Q., Hatano, M., and Morikawa, A., 1986b, The catalysts active and selective in oxidative coupling of methane. Alkali-doped samarium oxides, Chem. Lett., 467.

Otsuka, K., Liu, Q., Hatano, M., and Morikawa, A., 1986c, Synthesis of ethylene by partial oxidation of methane over the oxides of transition elements with $\mathrm{LiCl}$, Chem. Lett., 903.

Otsuka, K., Liu, Q., and Morikawa, A., 1986d, Selective synthesis of ethylene by partial oxidation of methane over $\mathrm{LiCl}-\mathrm{Sm}_{2} \mathrm{O}_{3}$, J. Chem. Soc., Chem. Commun., 586.

Otsuka, K., and Jinno, K., 1986, Kinetic studies on partial oxidation of methane over samarium oxides, Inorg. Chim. Acta, 121, 237.

Otsuka, K., and Komatsu, T., 1987, High catalytic activity of $\mathrm{Sm}_{2} \mathrm{O}_{3}$ for oxidative coupling of methane into ethane and ethylene, Chem. Lett., 483.

Otsuka, K., 1990, Activation and functionalization of methane, Future Opportunities in Catalytic and Separation Technology, Elsevier Science Publishers, Amsterdam, 105.

Ray, A., Tonkovich, A., Aris, R., and Carr, R., 1990, The simulated countercurrent moving-bed chromatographic reactor, Chem. Eng. Sci., 45(8), 2431.

Ray, A., Carr, R., and Aris, R., 1994, The simulated countercurrent moving-bed chromatographic reactor: a novel reactor-separator, Chem. Eng. Sci., 49(4), 469.

Scurrell, M., 1987, Prospects for the direct conversion of light alkanes to petrochemical feedstocks and liquid fuels- a review, App. Cat., 32, 1.

Sofranko, J., Leonard, J., and Jones, C., 1987, The oxidative conversion of methane to higher hydrocarbons, J. Catal., 103, 302.

Tonkovich, A., Carr, R., and Aris, R., 1993, Enhanced C2 yields from methane oxidative coupling by means of a separative chemical reactor, Science, 262, 221.

Tonkovich, A., Carr, R., and Aris, R., 1994, Experimental evaluation of designs for the simulated countercurrent separator, submitted to AIChE J.

Tong, Y., Rosynek, M., and Lunsford, J., 1989, Secondary reactions of methyl radicals with lanthanide oxides: their role in the selective oxidation of methane, J. Phys. Chem., 93, 2896. 

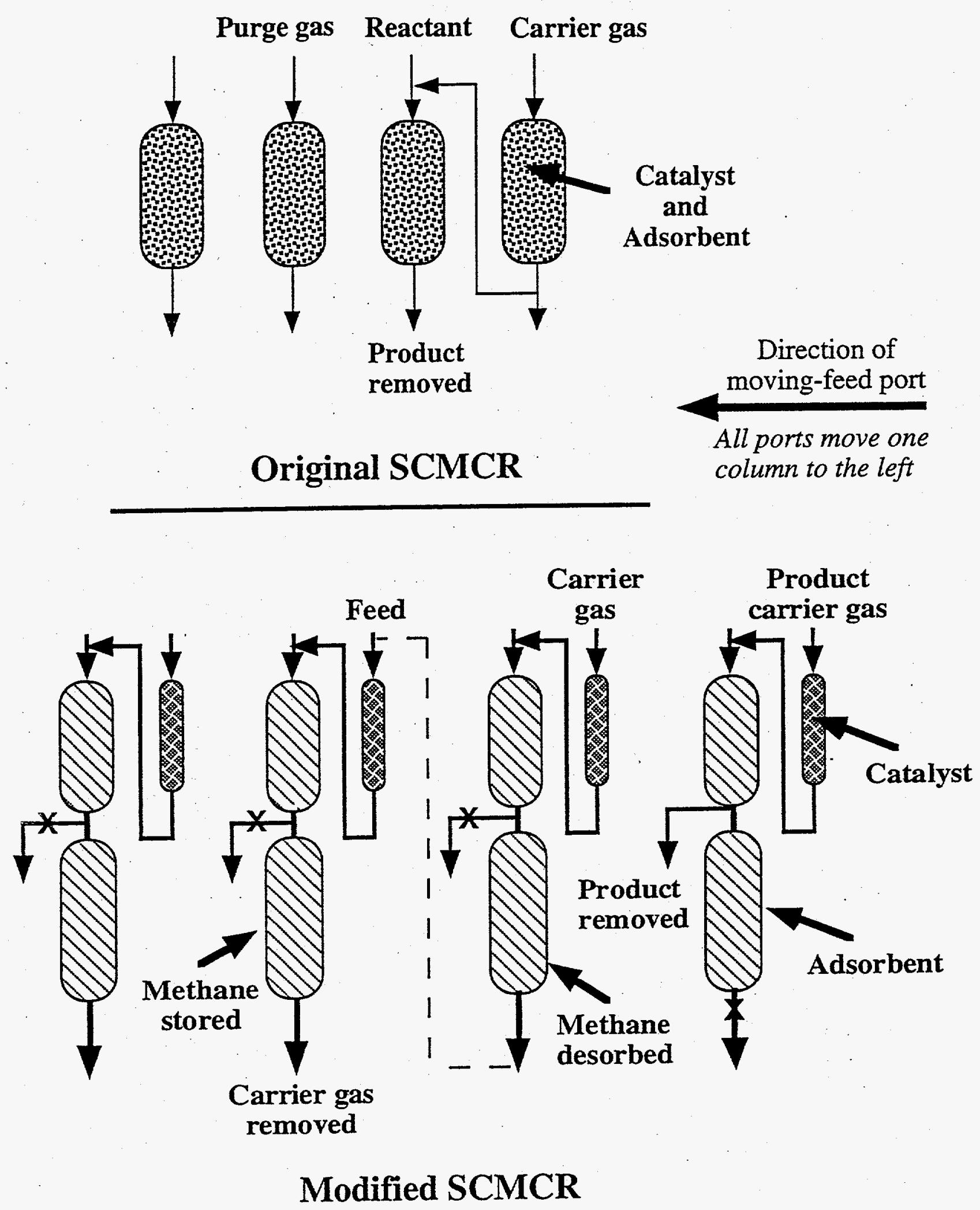

Figure 1: Original and Modified SCMCR configurations. 


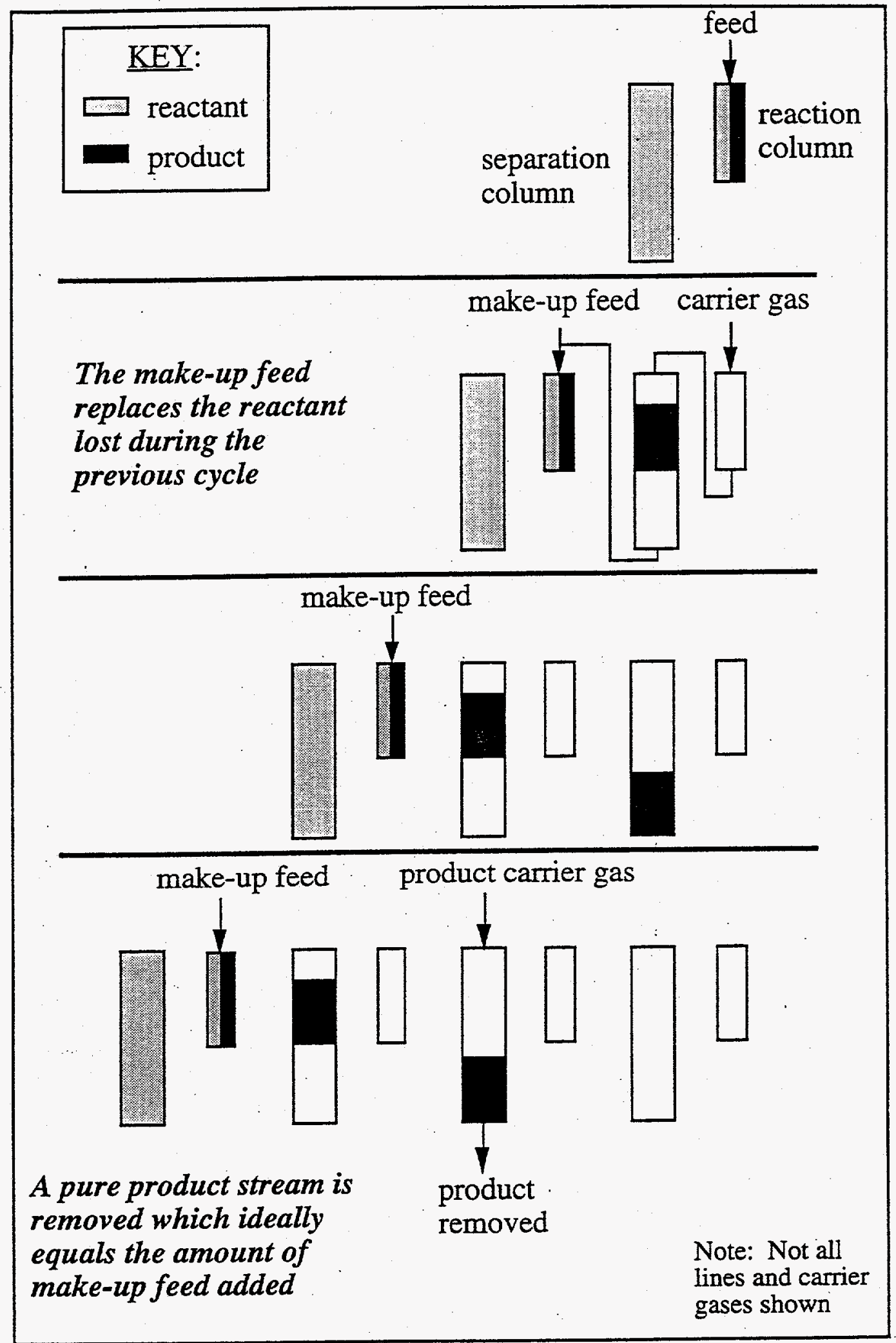

Figure 2: Ideal concentration profiles for the modified SCMCR. 


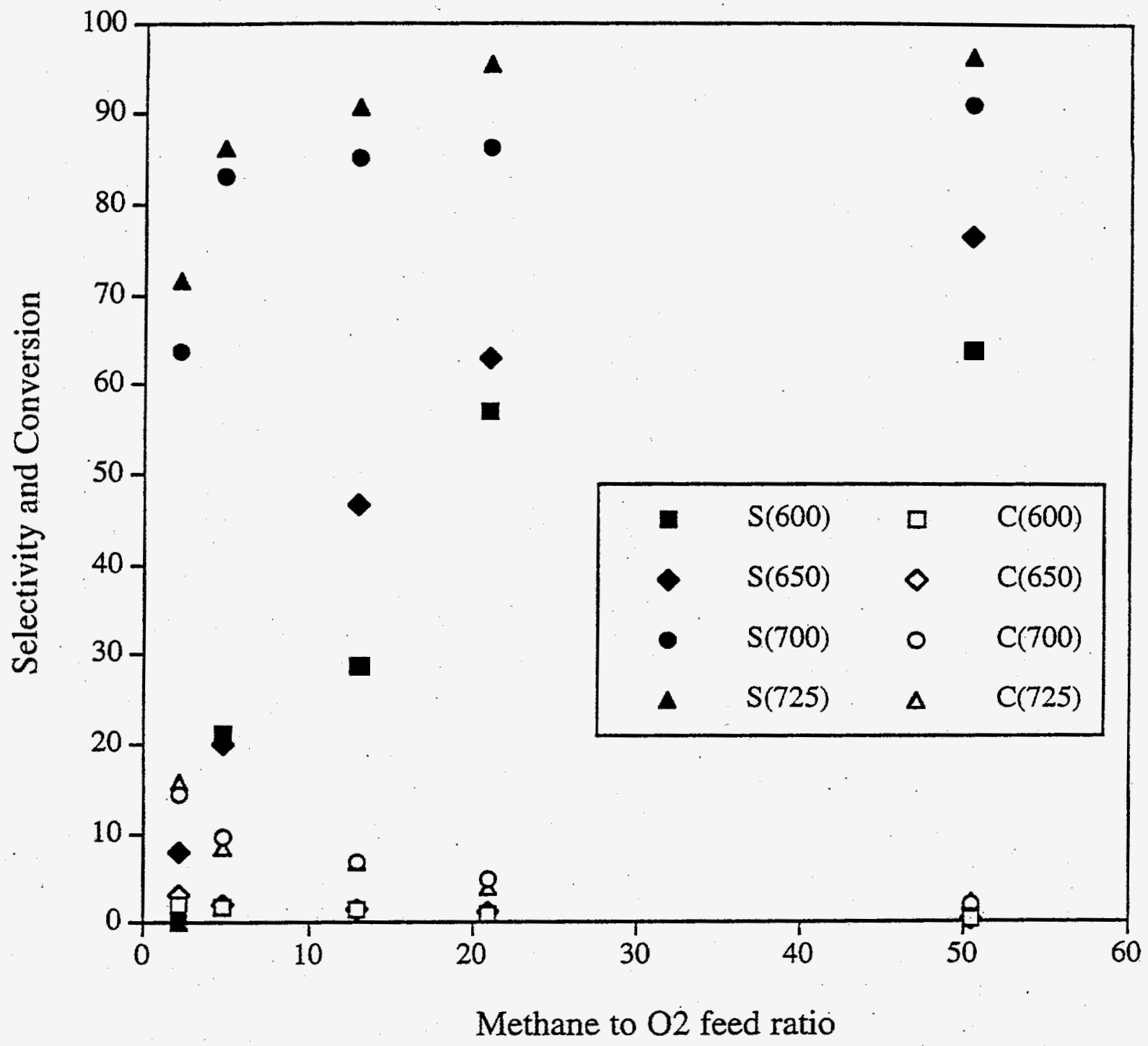

Figure 3: Microreactor results for samarium oxide catalyst for $\mathrm{T}=600,650,700$, and $725^{\circ} \mathrm{C}$. 


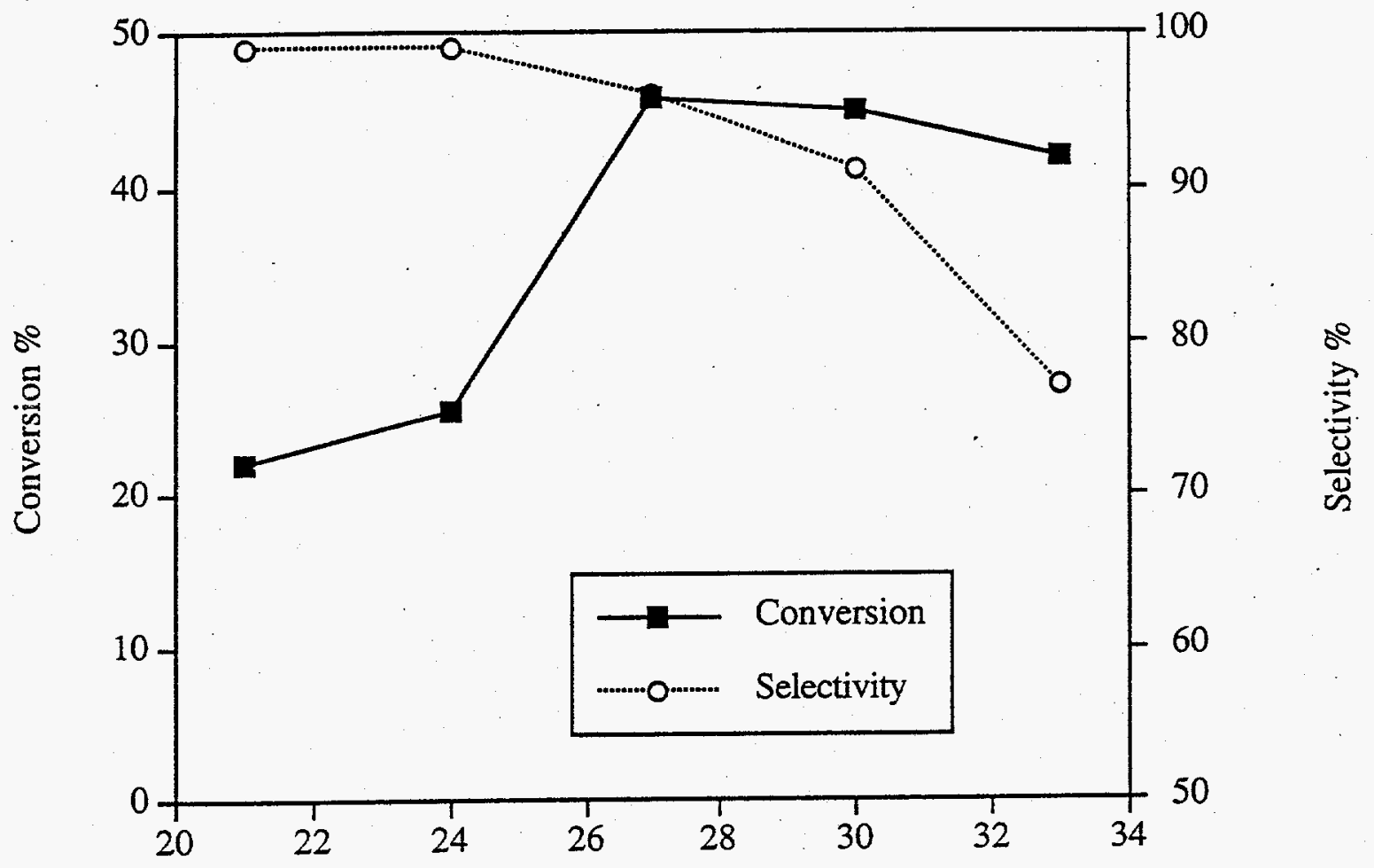

Feed switching time (seconds)

Figure 4: SCMCR performance at $700^{\circ} \mathrm{C}$. 


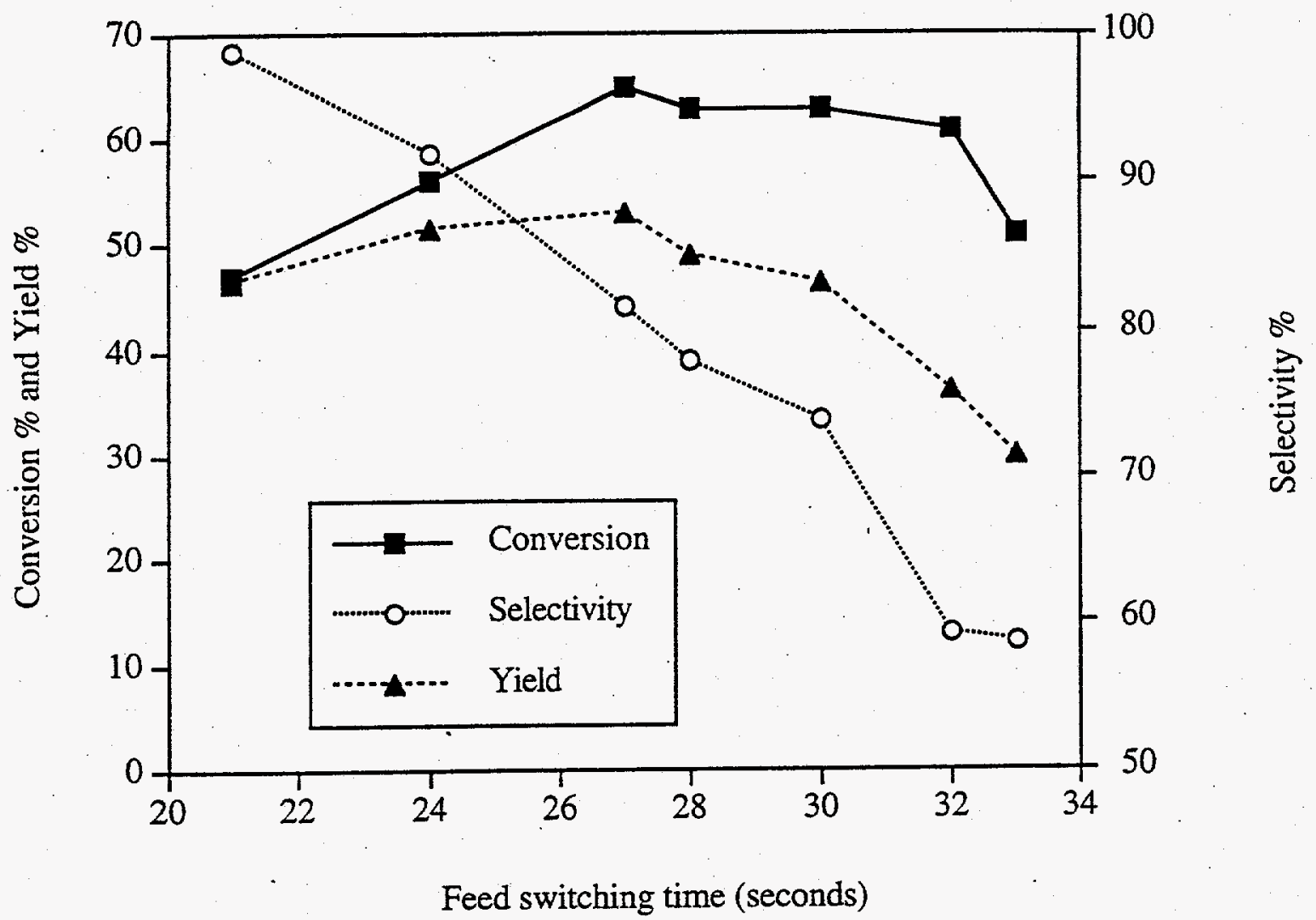

Figure 5: SCMCR performance at $725^{\circ} \mathrm{C}$. 


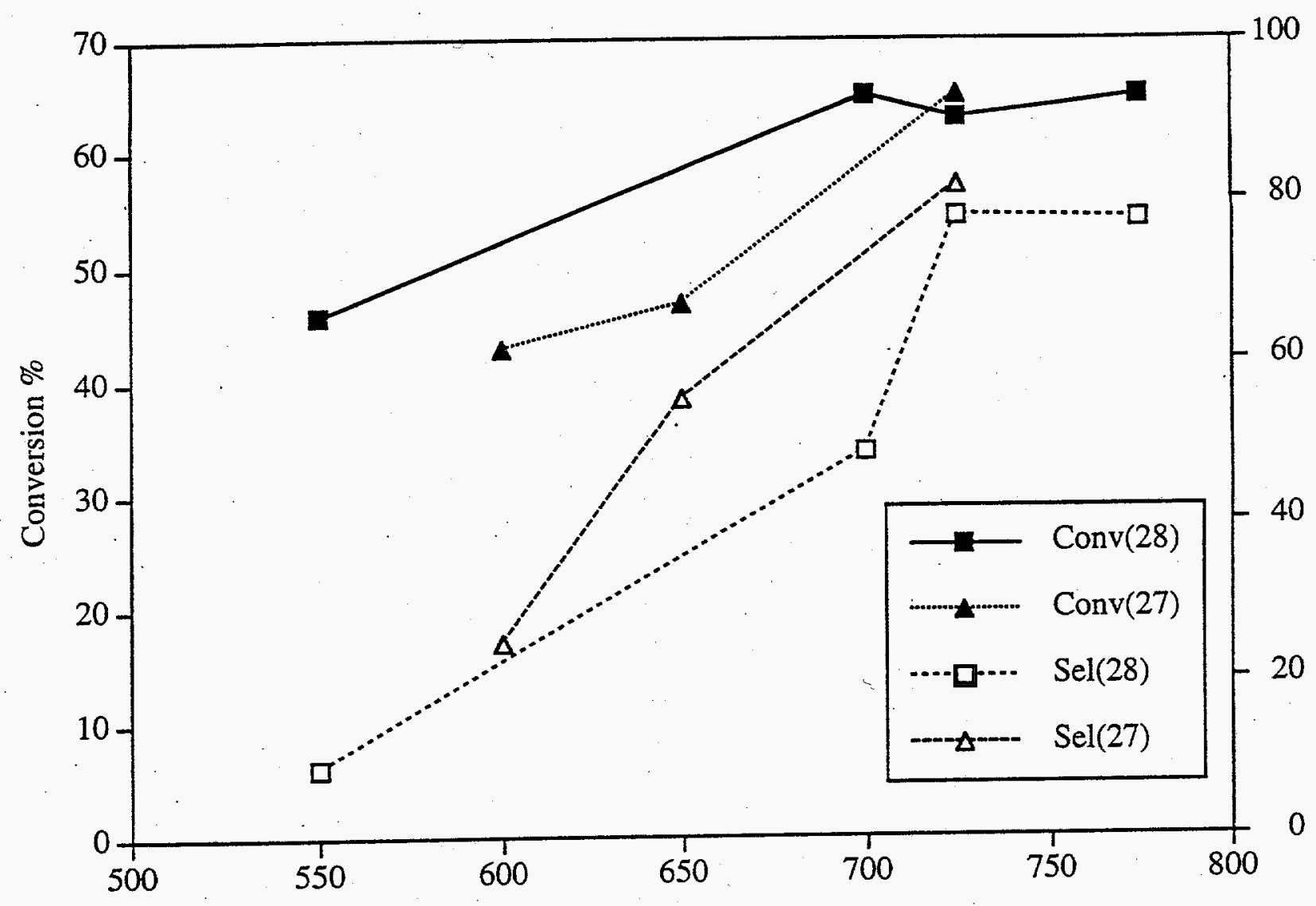

Temperature (C) Figure 6: SCMCR effect of temperature for switching times of 27 and $28 \mathrm{sec}$. The methane
breakthrough time is $34 \mathrm{sec}$. 


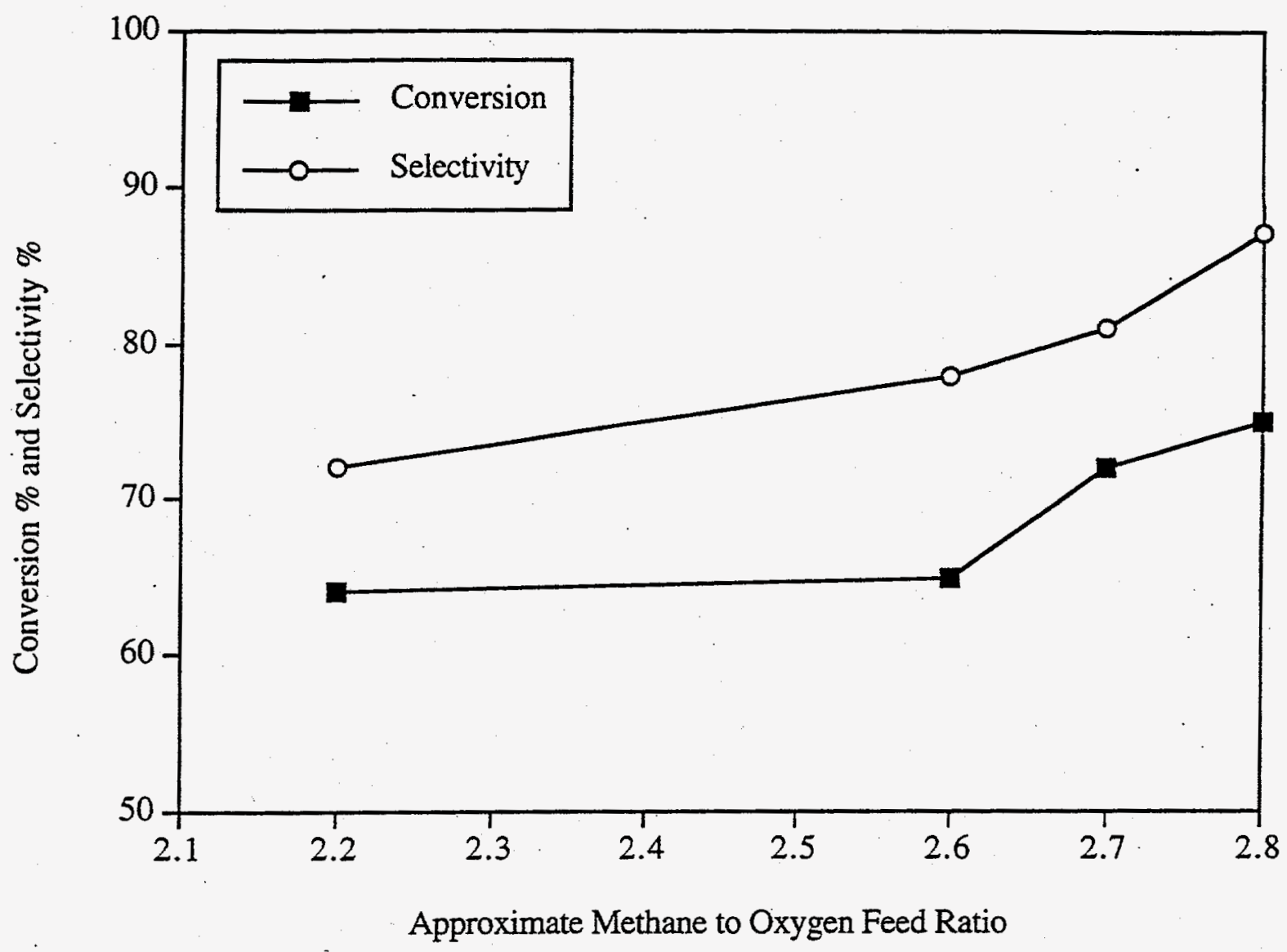

Figure 7: SCMCR effect of feed ratio for a switching time of $28 \mathrm{sec}$ and $775^{\circ} \mathrm{C}$. 